\title{
Health risk factors associated with pesticide use by watermelon farmers in Central region, Ghana
}

\author{
Michael K. Miyittah ${ }^{1,2^{*}} \mathbb{0}$, Moses Kwadzo ${ }^{3}$, Abigail Peprah Gyamfua ${ }^{1}$ and Daniel E. Dodor ${ }^{4}$
}

\begin{abstract}
Background: The export drive for watermelon production is huge and so is pesticide usage. However, the health and safety of the farmers, as well as threat to the environment lie in the shadow. The purpose of the study is to evaluate watermelon farmers' knowledge and application of pesticides in the Central region of Ghana, to ascertain factors associated with the pesticides application.
\end{abstract}

Methods: A field survey of 300 farmers were conducted in six communities through questionnaire. Logistic regression model was used to describe and explain burning sensation as the response variable and the factors that likely affect appropriate pesticide usage.

Results: The results show that farmers were aware of the environmental and health impacts of pesticides use. However, their knowledge of the risks associated with pesticides is not translated into actual practice to avoid the exposure of pesticides. The farmers experienced various levels of health risks symptoms. Health risks symptoms of headache, burning sensation, fever, watering eyes, chest pains, etc., were reported. The most common symptom is burning sensation. A model capturing biosocial factors influencing predisposition to burning sensation was developed. The model revealed that knowledge to identify pests, knowledge to identify diseases and wearing coverall were the most significant factors farmers experienced to influence burning sensation.

Conclusion: Significant number of watermelon farmers' experienced health risks symptoms. In order to minimize the health risk symptoms and environmental consequences, educational training programs must involve the farmers and retailers through strong policy intervention.

Keywords: Watermelon, Health risk, Smallholder farmers, Pesticides, Exposure

\section{Background}

In controlling pests and diseases affecting fruits and vegetables, food crops (yam, maize, rice, cassava), cocoa and watermelon for cultivation, smallholder farmers in Ghana and in Africa apply various pesticides (Wumbei and Houbraken 2019; Afari-Sefa et al. 2015; Kwadzo et al. 2015; Mattah et al. 2015; Ngowi et al. 2007). Reports from Wumbei and Houbraken (2019) revealed that

\footnotetext{
*Correspondence: m-miyittah@ucc.edu.gh

${ }^{1}$ Department of Environmental Sciences, University of Cape Coast, North

Campus, University Avenue, Science Building, Cape Coast, Ghana

Full list of author information is available at the end of the article
}

smallholder farmers were applying pesticides more than the recommended dose on yam, and do not take into consideration health protection when applying the pesticides in Northern part of Ghana. Similarly, work done by Afari-Sefa et al. (2015) in Ashanti and Western region of Ghana showed that farmers experienced health impacts of pesticides after application. Further, Kwadzo et al. (2015) investigated pesticides use and health hazards among small-scale commercial vegetable growers in the Eastern region of Ghana. The results showed that due to inadequate knowledge on personal protective equipment use during pesticide application, farmers were exposed to health risk factors of skin/eye irritation, but those with 
training and education on pesticide usage had low levels of health effects. The study further showed clearly the impact of education and training in minimizing the negative effects of pesticides and this is consistent with data from Ethiopia (Mesele et al. 2019).

Data from other parts of Africa, Northern Tanzania on pesticides use among smallholder vegetable farmers also demonstrated that vendors often dispensed smaller quantities of pesticides in unlabeled containers, and in addition about one-third of the farmers applied pesticides in mixtures of various doses. About $68 \%$ of the farmers reported having felt sick after routine pesticides application (Ngowi et al. 2007). In Botswana, Machekano et al. (2019) reported pesticides residues were detected in $74 \%$ of cabbage samples from three vegetable markets (farmgates, vendors and supermarkets), and such public health concerns of excess pesticides residues is also found in Ghana (Donkor et al. 2016; Osei-Fosu et al. 2017).

The above investigations on pesticides application and health impacts are indicating weak law enforcement of pesticides use in Africa, and untrained personnel in use of pesticides application. Generally, the farmers level of education is low and respective African governments are showing lackadaisical action on pesticides registration and control, for swift policy change to demonstrate how serious the problem is. As the pesticides contamination escalates, there is the need for analytical and environmental scientists to understand the sources of the pollution, the socio-behavioral drivers beneath the problem, and how to deal with residues of pesticides in crops and pollution in environmental media of soil and water.

In this study, we investigated pesticides use and application among watermelon farmers in Central region of Ghana. To the best of our knowledge scanty information is available in the literature regarding watermelon farmers' knowledge and behavior towards pesticides application. In this study it is hypothesized that inadequate knowledge in pesticides use would be associated with pesticide health risk factors among smallholder watermelon farmers in the Central region of Ghana. Specifically, our objectives were: (1) to assess farmers' knowledge and practices towards pesticides use; (2) to assess health risk factors associated with pesticides use.

\section{Materials and methods}

\section{The study area and data collection}

The study was conducted at the Komenda-Edina-EguafoAbirem (KEEA) Municipal, which is one of the twenty districts in the Central region of Ghana. The KEEA municipality is situated along the coastal zone with series of lagoons and wetlands. The lagoons include, Brenya, Brenu, Susu, Abrobi and Ankwanda which support a vibrant salt industry (GSS 2014). Elmina as the municipal capital is a major tourist destination in Ghana, having two UNESCO World Heritage protected sites; the castle of St. George d'Elmina and Fort Coenraadsburg on St. Jago Hill attracts over 100,000 visitors annually (GSS 2014). Agriculture (crop farming) and fishing are major economic activities in the municipality. In particular, the watermelon farming helps to supply watermelon fruits to the residents and tourists who often visit the World Heritage sites. Six communities along the coastal zone and within the district were selected for the study, namely; Nsadwir, Awona, Ayensudo-Junction, Enyinase, Abakano and Ayensudo-Newtown. These communities are bounded on the South by the Atlantic Ocean (Gulf of Guinea), the East by the Cape Coast Municipality, the North by the Twifo-Hemang-Lower Denkyira District and the West by the Mpohor-Wassa East District. Annual rainfall ranges between $750 \mathrm{~mm}$ and $1000 \mathrm{~mm}$ while in the more interior areas, it ranges between 1200 and $1500 \mathrm{~mm}$ (Ministry of Food and Agriculture 2015) (Fig. 1).

Descriptive research design was used for this study and data was collected through questionnaire. The questionnaire covered the following areas: demographic profile of farmers, knowledge of pesticide use and health risk factors associated with pesticides application. Three hundred watermelon farmers participated in the study. The population of our study includes all the 700 farmers within the KEEA who benefited from Ministry of Food and Agriculture (MoFA) extension services (anecdotal evidence from extension officer, MoFA). Our target population was watermelon farmers in the KEEA. Based on anecdotal knowledge from the extension officer, our target population was three-hundred and eighty watermelon farmers. However, due to lack of sample frame on the watermelon farmers, we collected data from 300 out of 380 watermelon farmers who were available and willing to participate in the research. The questionnaire was presented in English and majority of participants read and answer the questions themselves. However, for few of the participants, the researcher read out the translated questionnaire in their local language. Majority of the questions had answers available with only a few of them having open ended. In this study the participants were neither coerced nor financially induced to take part in the research. They were informed that the information provided will contribute to the overall knowledge about the effects of pesticide use on their health.

\section{Statistical analysis}

Univariate analysis involving simple percentage, frequency and mean scores were computed for respondents' socio-demographic variables and knowledge on pesticides. Ranking was computed to gain insight on farmer's need towards pesticide use and health symptoms 


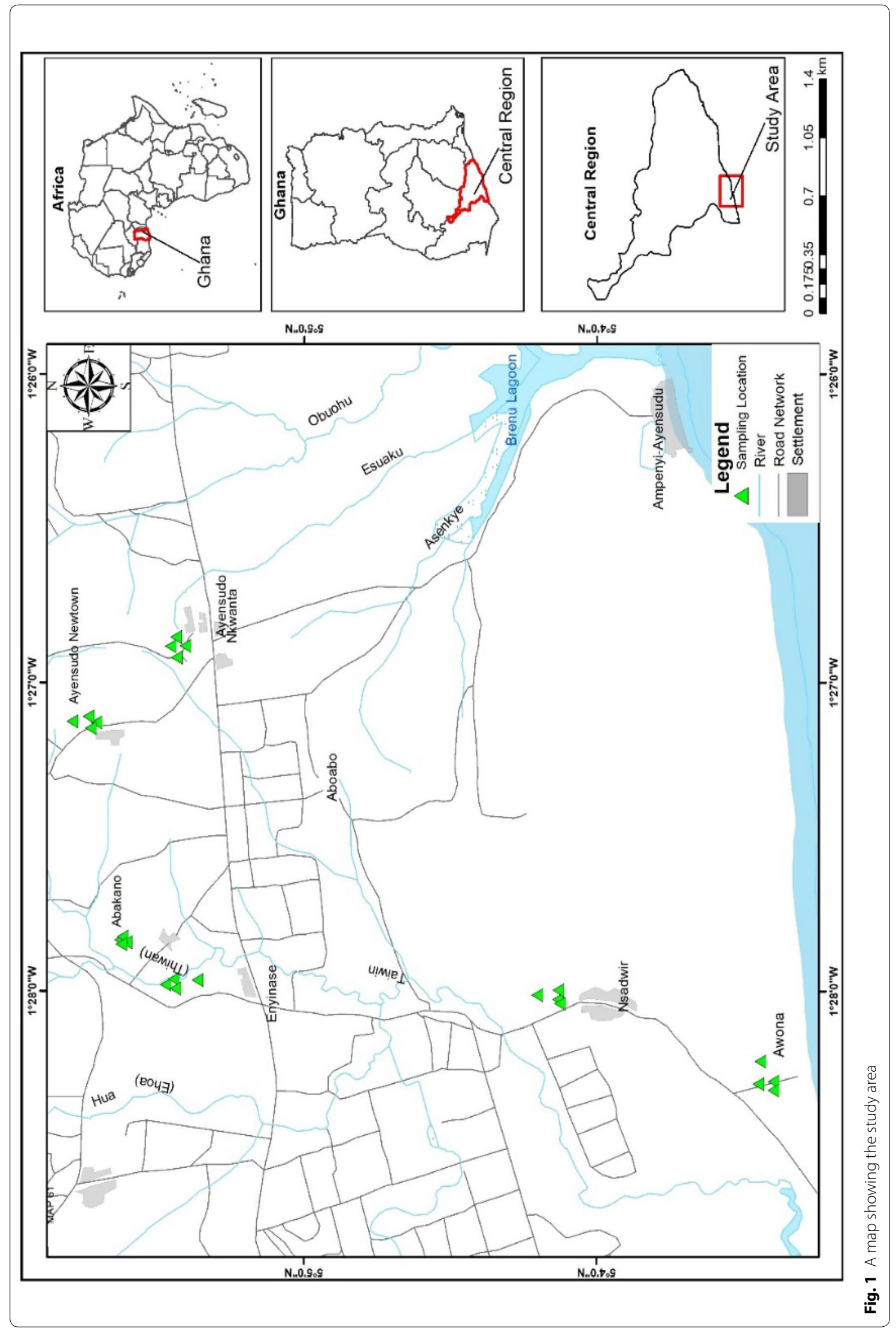


experienced due to pesticides application. Correlation was used to ascertain positive or negative relationships between the response and explanatory variables using Cramer's v. Multivariate analysis was used to gain further insights on factors associated with the response variable. Specifically, logistic regression model was used to describe and explain the relationship between response variable and explanatory variables. In this study, the researchers considered the outcome variable as burning sensation, since it is the foremost symptoms that majority reported as heat or sharp or prickly pain at any part of the body during or after the application of pesticides. Factors that likely affect appropriate pesticides usage includes but not limited to farmers' educational level, use of protective clothing, ability to read pesticides manual, ability to identify specific pests and diseases that affect a given fruit such as watermelon. The explanatory variables likely to affect the outcome variable (burning sensation) in this study were respondents educational level, wearing coverall, ability to read manufacturer's instruction, knowledge to identify watermelon related pests, and knowledge to identify watermelon related diseases. The logistic regression model provides transformed (logit) probability as a linear relationship with the predictor or explanatory variables. The probability $(\mathrm{p})$ of farmers experiencing burning sensation, is such that the logit (p):

$$
\begin{aligned}
& \log \operatorname{it}(\mathrm{p})=\ln \mathrm{p} / 1-\mathrm{p}=\ln (\text { odds ratio) } \\
& =\beta_{0}+\beta_{1} \mathrm{X}_{1}+\beta_{2} \mathrm{X}_{2}+\cdots+\beta_{\mathrm{k}} X_{\mathrm{k}}
\end{aligned}
$$

where $\mathrm{p}$ is the probability of burning sensation as affected by sets of explanatory variables and 1-p, the probability of not to be affected; and the odds ratio is the ratio of the two probabilities: $\mathrm{p} /(1-\mathrm{p}), \beta_{\mathrm{o}}=$ the constant of the equation, $\beta_{1}=$ the coefficient of the explanatory variables 1. And $\mathrm{X}_{1}, \ldots, \mathrm{X}_{\mathrm{k}}$ as sets of explanatory variables. Confidence interval was set at 95\%, Hosmer-Lemeshow goodness of fit test was used to find out how well the data fits the logistic model (Hosmer and Lemeshow 2010; Bewick et al. 2005).

For the avoidance of doubts regarding sample distribution and representativeness, bootstrap technique was used to provide additional support. Bootstrap is a resampling method which allows for estimation or approximating the sampling distribution of the statistics. It can be used to measure the accuracy of a given parameter estimate, and to provide additional strength in estimating the stability of the sample result, statistical model, and test parameters of SE (standard error of the mean) and CI (confidence interval). The bootstrap method does not require knowledge of the data generated, but uses the sample information as proxy population. The method takes a sample with replacement from the original sample and calculates the statistic of interest repeatedly (Islam and Begum 2018). Through this repeatedly resampling approach, bootstrap can be used to quantify the uncertainty associated with a given estimator or statistical method. In this study, the proxy sample population was 300 , and large sample size of 2000 was estimated in the bootstrapping. Bootstrapping is known to produce highly accurate results than traditional methods of estimating sample distribution of a statistic of interest, and is found to be applicable for both parametric and non-parametric tests (Efron 1979; Efron and Tibshirani 1993; Wright et al. 2011). All data were coded and analyzed using Statistical Package for Social Sciences (SPSS) version 20 (SPSS Inc, Chicago, IL, USA) and Microsoft Office Excel 2010 (Microsoft Corporation, Redmond, WA, USA). An alpha $(\alpha)$ level of $\leq 0.05$ was used as a criterion for statistical significance.

\section{Results}

The Socio-demographic profile

Table 1 presents the socio-demographic characteristics of farmers. The study revealed that $80 \%$ of respondents were males while the remaining $20 \%$ were females. It was evident from the results that males dominated in watermelon farming. Majority of the farmers $(40.7 \%)$ of the respondents had ages between 35 and 49 years and 30\%

\begin{tabular}{|c|c|c|}
\hline Variable & Frequency & Percentage \\
\hline \multicolumn{3}{|l|}{ Gender } \\
\hline Male & 240 & 80.0 \\
\hline Female & 60 & 20 \\
\hline \multicolumn{3}{|l|}{ Age (years) } \\
\hline$\geq 20$ & 6 & 2.0 \\
\hline $20-34$ & 90 & 30.0 \\
\hline $35-49$ & 122 & 40.7 \\
\hline$\geq 50$ & 82 & 27.3 \\
\hline \multicolumn{3}{|l|}{ Educational level } \\
\hline No formal education & 40 & 13.3 \\
\hline Primary education & 152 & 50.7 \\
\hline Secondary education & 100 & 33.3 \\
\hline Tertiary education & 8 & 2.7 \\
\hline \multicolumn{3}{|c|}{ Economic activity of household } \\
\hline Farming & 260 & 88 \\
\hline Secondary jobs & 40 & 12 \\
\hline \multicolumn{3}{|l|}{ Family size } \\
\hline $1-2$ & 10 & 3.3 \\
\hline $2-4$ & 58 & 19.3 \\
\hline$\geq 5$ & 226 & 75.3 \\
\hline None & 6 & 2.0 \\
\hline
\end{tabular}

Table 1 Socio-demographic profile of farmers 
of the respondents had ages between 20 and 34 years. Only $1.3 \%$ of the farmers were less than 20 years while $27.3 \%$ were above 50 years. On education, $13.3 \%$ of the farmers had no formal education, $50.7 \%$ primary education, $33.3 \%$ of farmers had secondary level education and $2.7 \%$, with tertiary education.

Most economic activity of the respondents was farming (88\%), and other secondary jobs (12.4\%) such as being engaged as a casual worker or having a small retailing business in addition to the main farming activity. Majority of respondents have family size of 5 and above (75.3\%) and the least family size of respondents was 1 or 2 representing $3.3 \%$. The data of the respondents show that they were smallholder farmers with $30.7 \%$ of the farmers with 3-4 acres of land, 5-6 acres (17.3\%), 1-2 acres (21.3\%) and $26 \%$ had more than 6 acres. Watermelon cultivation is their main activity with $74 \%$ engaging in it with other food crops like okra (20\%) were grown together (data not shown). The main occupation was farming (79.3\%), while others (18.7\%) engage in other occupation but the least occupation (2\%) was both farming and fishing (data not shown).

\section{Farmers knowledge on pesticides safety and use}

Table 2 shows farmers' knowledge on pesticides use and safety with respect to health effects, routes of exposure, environmental impacts, food safety, and pesticides use compliance. The farmers admitted that pesticides are detrimental to the health (80\%) with 144 farmers supporting that all pesticides have the same health effect. In addition, $79.3 \%$ of the respondents confirmed that pesticides can be dangerous. Knowledge on the route of entry of the pesticides was clearly understood with $88.7 \%$ identifying that pesticides can enter the body through inhalation, $90 \%$ of the respondents agreeing of the entry through the skin, and $86 \%$ mentioning that pesticides can enter the body through the mouth. $89.3 \%$ of the respondents are aware that pesticides residues can be left in the air, pesticides residues can be left in the soil (82\%), pesticides residues can be found in groundwater $(56.7 \%)$, pesticides residues can be found in fruits (54\%), pesticides residues can be found in vegetables (66\%). 58\% farmers responded that they read manufacturer's instructions, with $61.3 \%$ farmers said they respect manufacturers notification (Table 2). In addition, $91.3 \%$ farmers had no knowledge on any forbidden pesticides but $3.3 \%$ of farmers are aware that DDT is a forbidden pesticide, and with $4 \%$ of the respondents aware of the existence of forbidden pesticides, however, do not know them by name, and $1.3 \%$ did not show any response (data not shown).

\section{Pesticides acquisition knowledge and usage}

Table 3 shows how the farmers have access to the pesticides, why and how the farmers use the pesticides. The data shows that $52 \%$ farmers purchase pesticides at local agrochemical shops in village, while $40.7 \%$

Table 2 Farmers' knowledge on pesticides safety and use

\begin{tabular}{|c|c|c|c|c|c|c|}
\hline \multirow[t]{2}{*}{ Variables } & \multicolumn{2}{|l|}{ Yes } & \multicolumn{2}{|l|}{ No } & \multicolumn{2}{|c|}{ Not sure } \\
\hline & $\mathbf{N}$ & $\%$ & $\mathbf{N}$ & $\%$ & $\mathbf{N}$ & $\%$ \\
\hline \multicolumn{7}{|l|}{ Health effects } \\
\hline Pesticides cause negative health effect & 240 & 80.0 & 28 & 9.3 & 32 & 10.7 \\
\hline All pesticides have the same health effect & 144 & 48.0 & 110 & 36.7 & 46 & 15.3 \\
\hline Pesticides be dangerous to use & 238 & 79.3 & 32 & 10.7 & 30 & 10.0 \\
\hline \multicolumn{7}{|l|}{ Routes of exposure } \\
\hline Pesticides enter the body through inhalation & 266 & 88.7 & 32 & 10.7 & 2 & 0.7 \\
\hline Pesticides enter the body through the skin & 270 & 90.0 & 16 & 5.3 & 14 & 4.7 \\
\hline Pesticides enter the body through the mouth & 258 & 86.0 & 40 & 13.3 & 2 & 0.7 \\
\hline \multicolumn{7}{|l|}{ Environmental impacts } \\
\hline Pesticides residues be left in the air & 268 & 89.3 & 14 & 4.7 & 18 & 6.0 \\
\hline Pesticides residues be left in the soil & 246 & 82.0 & 22 & 7.3 & 32 & 10.7 \\
\hline Pesticides residues be found in groundwater & 170 & 56.7 & 96 & 32.0 & 34 & 11.3 \\
\hline \multicolumn{7}{|l|}{ Food safety } \\
\hline Pesticides residues be found in fruit & 162 & 54.0 & 112 & 37.3 & 26 & 8.7 \\
\hline Pesticides residues be found in vegetable & 198 & 66.0 & 78 & 26.0 & 24 & 8.0 \\
\hline \multicolumn{7}{|l|}{ Pesticides compliance } \\
\hline Read manufacturer notification & 174 & 58.0 & 114 & 38.0 & 12 & 4.0 \\
\hline Respect manufacturer regulation & 184 & 61.3 & 70 & 23.3 & 46 & 15.3 \\
\hline
\end{tabular}

$\mathrm{N}=$ number of respondents, (\%) indicates percentage 
Table 3 Pesticides acquisition, knowledge and use

\begin{tabular}{|c|c|c|}
\hline Variables & Frequency & Percentage \\
\hline \multicolumn{3}{|l|}{ Access to pesticides } \\
\hline Agrochemical shops in town & 122 & 40.7 \\
\hline Local agrochemical shops in the village & 156 & 52.0 \\
\hline Extension officers & 6 & 2.0 \\
\hline Cooperative societies & 2 & 0.7 \\
\hline Both agrochemical and local shops & 14 & 4.7 \\
\hline \multicolumn{3}{|l|}{ Why use pesticides } \\
\hline Protect crops against insects & 216 & 72 \\
\hline Make crops grow better & 40 & 13.3 \\
\hline Advised to use pesticides & 2 & 0.6 \\
\hline Make crops grow better & 38 & 12.6 \\
\hline Control weeds & 4 & 1.3 \\
\hline \multicolumn{3}{|l|}{ Knowledge to identify common pest disease } \\
\hline Yes & 240 & 80.0 \\
\hline No & 60 & 20.0 \\
\hline \multicolumn{3}{|l|}{ Knowledge to identify common crop disease } \\
\hline Yes & 144 & 48.0 \\
\hline No & 156 & 52.0 \\
\hline \multicolumn{3}{|l|}{ Time to apply pesticides } \\
\hline Presence of pest & 208 & 69.3 \\
\hline Degree of pest infestation & 16 & 5.3 \\
\hline Date of planting & 66 & 22.0 \\
\hline On calendar spray schedules & 10 & 3.3 \\
\hline \multicolumn{3}{|l|}{ Knowledge of pesticides application methods and rate } \\
\hline Agrochemical shops & 86 & 28.7 \\
\hline Extension officers & 48 & 16.0 \\
\hline Pesticides labels on packages & 40 & 13.3 \\
\hline Fellow farmers & 104 & 34.7 \\
\hline Both agrochemical shops and extension officers & 2 & 0.7 \\
\hline Both agrochemical shops and fellow farmers & 4 & 1.3 \\
\hline Own experience & 16 & 5.3 \\
\hline \multicolumn{3}{|l|}{ Dilute pesticide before application } \\
\hline Mix more than one types of pesticides with water in container & 264 & 88.0 \\
\hline Mix one type of pesticides with water in a container & 32 & 10.7 \\
\hline Depending on the instructions on the label & 4 & 1.3 \\
\hline
\end{tabular}

acquire theirs at agrochemical shops in town. The data shows that, $72 \%$ of the farmers use pesticides to protect crops against insects while $13.3 \%$ use it for better crop growth. Also, $12.6 \%$ of the farmers use pesticides because of insects as well as to make crops grow better. Only few farmers $(1.3 \%$ and $0.6 \%)$ use pesticides because of both insects and to control weeds; because the individual was advised. $80 \%$ of the farmers were able to identify common pest disease but $52 \%$ were unable to identify common crop disease. $69.3 \%$ of the farmers apply pesticides at the presence of pest but $5.3 \%$ use it during the degree of pest infestation. 3.3\% of the farmers administer pesticides on calendar spraying schedules where as $22 \%$ apply pesticides using the date of planting. The knowledge of pesticides application methods and rates were obtained from fellow farmers (34.7\%), agrochemical shops (28.7\%), extension officers (16\%), pesticides labels on packages (13.3\%), own experience $(5.3 \%)$. Before spraying, $88 \%$ of the respondents' mix more than one types of pesticides with water in container, $10.7 \%$ dilute one type of pesticide with water in a container and $1.3 \%$ use the instructions labeled on the container (Table 3). 
Practices on use of protective wear, storage and disposal of pesticides

The responses of pesticide applicators to questions related to use of protective wear, disposal of empty containers, storage location of pesticides, washing of sprayers and period of last spraying before selling are presented in Table 4. On the question of the reason for not using protective wear during pesticides application, about one-fourth (39\%) of the respondents gave the high cost of buying personal protective gear as the main contributing factor. Similarly, about $13.3 \%$ of the respondents were reluctant to use protective wear due to general lethargy and feel discomfort especially in the hot and humid climate of the study area. Also from observations, there existed no monitoring mechanism to ensure continue use.

With reference to the disposal of empty pesticides containers after use, interestingly, the respondents used

Table 4 Use of protective wear; disposal of empty containers after use; storage location of pesticides; washing of sprayers; and period of last spraying before selling

\begin{tabular}{|c|c|c|}
\hline Variables & Frequency & Percentage \\
\hline \multicolumn{3}{|l|}{ Reason for not using protective wear } \\
\hline No response & 30 & 10 \\
\hline High buying cost & 118 & 39.3 \\
\hline Do not feel comfortable in them & 40 & 13.3 \\
\hline Do not have it & 32 & 10.7 \\
\hline Not interested & 12 & 4.0 \\
\hline Others & 68 & 22.7 \\
\hline \multicolumn{3}{|l|}{ Disposal of empty pesticides container } \\
\hline Put in other uses & 62 & 20.7 \\
\hline Throw away on the farm & 140 & 46.7 \\
\hline Throw away in the village & 52 & 17.3 \\
\hline Burry in the ground on the farm & 26 & 8.7 \\
\hline Burn on the farm & 18 & 6 \\
\hline Others & 2 & 0.7 \\
\hline \multicolumn{3}{|c|}{ Disposal of remnant of pesticides after end of application } \\
\hline On field & 230 & 76.7 \\
\hline Throw in river, lakes or irrigation canal & 4 & 1.3 \\
\hline Leave it for next spraying time & 24 & 8.0 \\
\hline Apply on the farm again & 6 & 2.0 \\
\hline Other & 36 & 12.1 \\
\hline \multicolumn{3}{|l|}{ Pesticides storage by respondents } \\
\hline Animal houses & 2 & 1.3 \\
\hline Living room & 140 & 46.7 \\
\hline In the bush & 84 & 28 \\
\hline In the kitchen & 48 & 16 \\
\hline In the food store & 2 & 0.7 \\
\hline Others & 24 & 7.4 \\
\hline \multicolumn{3}{|c|}{ Where they wash sprayers after application of pesticides } \\
\hline In the river, lake or irrigation canal & 52 & 17.3 \\
\hline At home using tap or bucket water & 66 & 22.0 \\
\hline Do not wash & 22 & 7.3 \\
\hline On the farm with the leftover water & 160 & 53.3 \\
\hline \multicolumn{3}{|l|}{ Period for last spraying to selling of crops } \\
\hline $1-2$ days & 28 & 9.3 \\
\hline $3-6$ days & 100 & 33.3 \\
\hline 1 week & 42 & 14.0 \\
\hline$>1$ week & 130 & 43.3 \\
\hline
\end{tabular}


unscientific way of disposal, as $45.7 \%$ of them throw away empty pesticides containers on their farms. This social behavior coupled with disposal of remnant pesticides after end of application accounted for $76.7 \%$ of the respondent's behavior. Thus, this is suggesting that pesticides ecological impacts may be coming from these sources.

When asked how they stored pesticides, several practices emerged. Almost, one-fourth of the respondents (46.7\%) stored pesticides in their living rooms. This is followed closely by $28 \%$ of the respondents stating that they stored the pesticides in the bush, which has no guarantee of safety to the environment or public health. Surprisingly however, some of the farmers (16\%) reported storing the pesticides in the kitchen. Pesticides stored in the home can easily contaminate drinking water and food and can threaten the health and safety of growing children in the home.

Bizarrely, when asked where they wash the sprayers after application of pesticides, more than half of the respondents (53.3\%) indicated that they wash on farms, and with $17.3 \%$ stating that they wash the sprayers in rivers, lakes or irrigation canal. Incidentally some of the sources of drinking water of the community is from the same river that they pollute. In addition, the water bodies are the source of fish and many habitats of aquatic organisms. The above methods of storing disposing of pesticides containers need critical interventions, so that awareness of public health concerns and safety during pesticide application can be enhanced (Jin et al. 2017; Jallow et al. 2017).

With reference to the last spraying to the selling of crops, several observations came to the fore. About onethird (33.3\%) of the respondents sell the crops after spraying between 3 and 6 days. Majority of the respondents, about one-fourth (43.3\%) stated, selling the crop after 1 week spraying (Table 4). The varying responses from the farmers indicate the inconsistencies with regulatory practices and the dangers of pesticides residues on crops from the local farmers. Anecdotal evidence shows that there are no regulatory agents at the point of sales crosschecking the public health safety of watermelons release for public consumption. Watermelons are transported directly from the farm gate to the nearest urban road for distribution to market centers across the country.

\section{Famers need towards pesticides use}

In order to promote appropriate use of pesticides among the respondents, their need was assessed by asking them to respond to a number of questions related to their pesticides knowledge need, knowledge on minimal health risk, precaution to be taken, limit use of pesticides etc.

Farmers responses include the option on a scale of 1 to 5 ; strongly disagree (1), disagree (2), don't know (3), agree (4), and strongly agree (5). As presented in Table 5, what farmers' need the most to achieve proper pesticides use was precautions in pesticides use with a mean score of 4.31 and ranked the highest on the scale, and with $99.3 \%$ of the respondents agree and strongly agree on the question. The second need of the farmers was pesticides use to protect crops with a mean score of 3.41. These firsttwo scores implied that the respondents desire is to know more about pesticide and the need to know how pesticide helps to protect their crops against pests and disease infestation. Key intervention needed is training regarding pesticides usage so as to enforce the necessary precaution required by the farmers.

As shown on Table 5, the 4th and the 5th scores suggest lack of clear understanding of the respondents on the need of pesticides effects on human health and the need to limit the use of pesticides. The median score for pesticides knowledge needed is 3.38 on the five point Likert scale, implying that the respondents have the desire to know more about pesticides and its' application.

\section{Use of protective wears and health risk}

Respondents were asked to indicate the protective measures they use during pesticides application. These measures were the use of gloves to protect the hand, use of goggles to protect the eyes against incidental and accidental pesticides droplets to affect the eyes, wearing special boots, oral or nose masks for protection against inhalation and wearing coverall. The use of protective measures during pesticides application is presented in

Table 5 Farmers need towards pesticides use

\begin{tabular}{|c|c|c|c|c|c|c|c|}
\hline Variables & Strongly disagree & Disagree & Don't know & Agree & Strongly agree & Mean score & Rank \\
\hline Precautions in pesticides use & - & $2(0.7)$ & - & $202(67.3)$ & $96(32.0)$ & 4.31 & $1 \mathrm{st}$ \\
\hline Pesticides protect crops & - & $2(0.7)$ & - & $172(57.3)$ & $126(42)$ & 3.41 & 2nd \\
\hline Pesticides knowledge & $2(0.7)$ & $10(3.3)$ & $16(5.3)$ & $150(50.0)$ & $122(40.7)$ & 3.38 & $3 \mathrm{rd}$ \\
\hline Limit use of pesticides & $6(20)$ & $48(16.0)$ & - & $210(70.0)$ & $36(12)$ & 2.92 & 4 th \\
\hline Knowledge on minimal health risks & $32(10.7)$ & $62(20.7)$ & $4(2.7)$ & $158(52.7)$ & $44(14.7)$ & 2.73 & 5 th \\
\hline
\end{tabular}

Values in parenthesis indicate percentages 
Table 6 Use of protective measures during pesticides application

\begin{tabular}{lrlll}
\hline Protective Gears & Yes & Percentage & No & Percentage \\
\hline Gloves & 80 & 26.7 & 220 & 73.4 \\
Goggles & 44 & 14.7 & 256 & 85.3 \\
Something on the head & 154 & 51.3 & 146 & 48.7 \\
Special boots & 188 & 62.7 & 112 & 37.3 \\
Oral/nose masks & 64 & 21.3 & 236 & 78.7 \\
Coverall & 90 & 30.0 & 210 & 70.0 \\
\hline
\end{tabular}

Table 6. A majority $73.4 \%$ of the respondents reported they do not use gloves during pesticides spraying. Similarly, $85.3 \%$ reported not using goggles to protect their eyes during application. On the other hand, 51.3\% reported they use something to cover the head, and $62.7 \%$ also on the affirmative that they wear special boots.

Further, 78.7\% reported not using oral or nose masks and $70 \%$ of the responses indicated not wearing coverall before spraying the crops with pesticides. The result in Table 6 shows clearly that the farmers were most likely exposed to health risks due to pesticides application since basic personal protection is inappropriately addressed.

\section{Health risk symptoms experienced due to pesticides use}

Pesticides can cause health risks and damages during short term application and long term use. Several health symptoms were reported by the respondents which is buttressing that, the farmers lack critical use of protective measures during spraying. As seen in Table 7, the most frequently reported symptoms were burning sensation $(78 \%)$, headaches $(67 \%)$, weakness $(60.7 \%)$, fever (64\%), watering eyes $(60.7 \%)$, itching and skin irritation (63\%), and chest pain (68\%). The ranking of burning

Table 7 Health symptoms experienced due to pesticides use

\begin{tabular}{lccc}
\hline Symptoms & No & Yes & Rank \\
\hline Burning sensation & 66 & 234 & 1 st \\
Chest pain & 94 & 206 & 2 nd \\
Headache & 98 & 202 & 3 rd \\
Fever & 108 & 192 & 4 th \\
Itching and skin irritation & 112 & 188 & 5 th \\
Weakness & 118 & 182 & 6 th \\
Watering eyes & 118 & 182 & 6 th \\
Dizziness & 166 & 134 & 7 th \\
Skin rashes & 168 & 132 & 8 th \\
Forgetfulness & 240 & 60 & 9 th \\
Diarrhea & 254 & 46 & 10 th \\
Vomiting & 272 & 28 & 11 th \\
\hline
\end{tabular}

sensation as number one, suggested that it is a common issue and burning sensation is a function of several drivers leading to health risk predisposition. These drivers could be biosocial or biophysical factors. These factors must be tested to help elucidate clearly the contributing risk variables.

\section{Relationship between burning sensation and explanatory variables}

From literature factors such as gender, age, use of PPEs, education, farm size, knowledge of pest and diseases presence, and years of farming experience (Lorenz et al. 2012; Kwadzo et al. 2015; Wumbei and Houbraken 2019) may influence on watermelon farmers' experience of burning sensation when applying pesticides. Correlation between burning sensation and various explanatory variables were computed using Cramer's $\mathrm{v}$ and presented in Table 8. The result of the association between burning sensation and explanatory variables indicated positive, negative and one ambiguous relationships, although some were not significant. This implies that various explanatory variables have some relationship with the dependent variable and therefore deem appropriate in the logistic model, which was tested in Table 9. Four factors were significant $(\mathrm{p}<0.05)$, which are gender, age, knowledge to identify crop pest and knowledge to identify crop disease to burning sensation. In contrast, low educational level, reading to manufacturer instruction and wearing coverall showed no significant relationship with burning sensation during pesticide usage.

\section{Logistic regression modeling}

There are several factors that might cause farmers to be predisposed to health risks. Burning sensation is taken as a dependent variable since it is one of the first signs or symptoms that the farmers will experience as a result of not wearing protective gears and/or with other variables. We modeled the factors that might be the drivers

\begin{tabular}{|c|c|c|}
\hline Variables & Sign & Significance \\
\hline Gender & Ambiguous ( \pm ) & s \\
\hline Age & + & s \\
\hline Low educational & + & ns \\
\hline Reading manufacturer's instruction & + & ns \\
\hline Knowledge to identity crop pest & - & s \\
\hline Knowledge to identity crop disease & + & s \\
\hline Wearing of cover all & - & ns \\
\hline
\end{tabular}

Significant for coefficient: $\mathrm{p}<0.05$; $\mathrm{s}$ for significant and $\mathrm{ns}$ for non-significant; + and - signs indicate positive or negative correlation 
Table 9 Factors likely to predispose burning sensation using logistic regression model

\begin{tabular}{|c|c|c|c|c|c|c|}
\hline \multirow[t]{2}{*}{ Variables } & \multirow{2}{*}{$\begin{array}{l}\text { Estimated } \\
\text { parameter (B) }\end{array}$} & \multirow{2}{*}{$\begin{array}{l}\text { Standard error } \\
\text { (SE) }\end{array}$} & \multirow[t]{2}{*}{ Wald } & \multirow[t]{2}{*}{ p-value } & \multicolumn{2}{|l|}{$95 \% \mathrm{Cl}$} \\
\hline & & & & & Lower & Upper \\
\hline Read manufacturer's instructions & -0.169 & 0.299 & 0.321 & 0.571 & 0.470 & 1.516 \\
\hline Knowledge to identify pest & -0.941 & 0.426 & 4.882 & $0.027^{*}$ & 0.169 & 0.899 \\
\hline Knowledge to identify disease & 0.795 & 0.299 & 7.091 & $0.008^{* *}$ & 1.234 & 3.976 \\
\hline Wear coverall & -0.634 & 0.311 & 4.161 & $0.041^{*}$ & 0.289 & 0.975 \\
\hline Low education & -0.450 & 0.311 & 2.089 & 0.138 & 0.346 & 1.174 \\
\hline
\end{tabular}

Hosmer and Lemeshow test $=(0.55, \mathrm{p}>0.05)$

* Indicates statistically significant level $p<0.05$; ${ }^{* *} p<0.01$

influencing burning sensation using logistic regression. In this model, our explanatory variables were ability to read manufacturer's instructions, knowledge to identify pest, knowledge to identify diseases, wearing coverall, and low education (no formal and/or primary education). These variables were selected after testing for multicollinearity among several variables. The explanatory variables were found to have a tolerance level of at least 0.953 , and in addition these variables were retained since they yielded a good fit model with Hosmer and Lemeshow test greater than 0.5 . The logistic model is presented in Eqs. (1) and (2), respectively. The burning sensation is a dichotomous dependent variable and specified as Yes $=1$ and $0=$ otherwise. And as in Eq. (2), $X_{1}, \ldots, X_{k}$ are the explanatory variables and with coefficient $\beta$. Using Eq. (2) we run the model and presented the result in Table 9. The Hosmer and Lemeshow test $=0.55, \mathrm{p}^{>} 0.05$ indicating that the model is well fit and confirms the significance of some of the selected explanatory variable at $\mathrm{p}<0.05$. Also, the Wald tests of the explanatory variables are all greater than zero indicating that the parameters are associated with the dependent variable.

In Table 9 and from the model, three main explanatory variables were found to be statistically significant to influence the farmers' likelihood to experience burning sensation in their usage of agrochemicals. The coefficient for farmers with knowledge to identify pest is negative and significant $(\beta=-0.941$, C.I. $=0.169-0.899 ; \mathrm{p}=0.027)$. Thus, the coefficient indicates that if a farmer has knowledge to identify pest, he or she would have a lower probability in experiencing a burning sensation during pesticide application. Conversely, the coefficient for the famers with knowledge to identify disease is positive and significant $(\beta=0.795$, C.I. $=1.234-3.976, p=0.008)$, which is surprising since farmers' knowledge to identify disease should be associated with less likelihood to experience burning sensation during pesticides application. This observation might likely be due to the fact that farmers' ability to identity disease is more difficult and required technical expertise. On the other hand, the coefficient for wearing coverall was negative and significant $(\beta=-0.634$, C.I. $=0.285-0.975, p=0.041)$. Thus indicating that, farmers wearing coverall are 0.63 times less likely to experience burning sensation than farmers who do not wear coverall. Although low education and ability to read manufacturers' instructions were expected to influence the farmer's likelihood to experience burning sensation during pesticides application, their estimated parameters were not significant but with positive association with the outcome variable. However, in this case the variables are not significant because education is componential in structure since continuous education is critical in achieving appropriate agronomic practices. Farmers low level of education might have accounted for the nonsignificant of their ability to read manufacturer's instructions. Intervention strategy like regular training is needed to have reduce impacts on burning sensation during pesticide application.

\section{Bootstrapping the model statistics}

In order to confirm the model statistics, and avoid doubts of sample distribution, bootstrapping was used as an additional technique to measure the accuracy of the logistic parameter estimates. Table 10 shows the result of the bootstrapping. In this study, a sample size of 300 as obtained from the survey is used as a proxy population. The bootstrap method estimates the sampling distribution empirically using the given sample size and estimate the parameters on large scale of 2000 sample size. In this way, bootstrapping serves as an internal replication mechanism for assessing the stability and replicability of sample results (Efron 1985; Thompson 1993). The results show that there are no differences between the standard errors in Table 9 for logistic regression and that of the bootstrap method in Table 10. In addition, the p-values were identical as predicted by both logistic regression and bootstrap method. The obvious implication is that 
Table 10 Bootstrap results generated after 2000 samples using proxy sample population

\begin{tabular}{|c|c|c|c|c|c|}
\hline \multirow[t]{2}{*}{ Variables } & \multirow{2}{*}{$\begin{array}{l}\text { Estimated parameter } \\
\text { (B) }\end{array}$} & \multirow[t]{2}{*}{ Standard error (SE) } & \multirow[t]{2}{*}{ p-value } & \multicolumn{2}{|l|}{$95 \% \mathrm{Cl}$} \\
\hline & & & & Lower & Upper \\
\hline Read manufacturer's instructions & -0.169 & 0.330 & 0.604 & -0.854 & 0.445 \\
\hline Knowledge to identify pest & -0.941 & 0.608 & $0.037^{*}$ & -2.223 & -0.128 \\
\hline Knowledge to identify disease & 0.795 & 0.310 & $0.007^{* *}$ & 0.230 & 1.465 \\
\hline Wear coverall & -0.634 & 0.325 & $0.038^{*}$ & -1.295 & -0.024 \\
\hline Low education & 0.450 & 0.313 & 0.136 & -0.125 & 1.108 \\
\hline
\end{tabular}

Hosmer and Lemeshow test $=(0.55, \mathrm{p}>0.05)$

* Indicates statistically significant level $p<0.05 ;{ }^{* *} p<0.01$

the sample size distribution and parameter estimates were accurate and correctly predicted by the model.

\section{Discussion}

In order to have sound educational policies and strategies, it is necessary to understand farmers level of knowledge and practices regarding pesticides application. This is to prevent ecological damage and health risk among watermelon farmers. In this study, a considerable number of farmers with more than $60 \%$ (no formal and primary level) of education, were engaged in pesticide application. Their level of understanding the hazards associated with pesticide use was so poor. Majority of the farmers (Table 2) indicated that they know the hazards and the health impacts associated with pesticides application. However, that understanding did not reflect or translate into precautionary measures that must be put in place i.e. wearing of protective gears and reading manufacturer's instruction before pesticide use. Our result is consistent with report from Wumbei and Houbraken (2019) in which yam farmers were exposed to various levels of pesticide hazards. Similar nature of exposure was recorded by Strong et al. 2008 in which the authors called for multiple stakeholder engagement in order to have a holistic approach in controlling the exposure. On the other hand, Feola and Binder (2010) described the farmers' attitudes of knowing the hazardous nature of pesticides and still engaged in such dangerous practices without precautionary measures due to lack of understanding social norms. Although factors associated with social norms were not addressed in this study, it is concurred that structural changes are needed to have behavioral change at a collective and systematic level.

On the issue of access and acquisition of pesticides, majority of the farmers (92.7\%) buy the pesticides from local agrochemical shops in town and village. Thus suggesting that agrochemical shop retailers must be included in the chain of educational training regarding pesticides distribution and their proper usage. Retailers are necessary because the farmer-extension officer ratio is so low within the region and the country and can help prevent the misconception of application rate error to avoid repetition and error propagation. Extension services and related programs have been noted to improve farmers condition (Danso-Abbeam et al. 2018). As can be observed that $88 \%$ of the farmers mixed more than one type of pesticides with water before spraying. This practice must be unlearned as information across the region is indicating negative impacts of pesticides use on bees' pollination (Thompson 2010; Johnson et al. 2010).

Table 4 shows clearly that farmers acclaimed knowledge regarding hazards of pesticide is not translated into actual practice as can be seen with the manner they dispose empty pesticides containers, where they store pesticides and how they wash the sprayers after use. Surprisingly and troubling is the fact that they put the empty container to other use, and even stored the pesticides in the living room by almost half of the respondents (46.7\%). These actions predispose the growing child in the family to severe risks if expose to the hazards. On the contrary in developed countries, critical control points were established where empty containers, pesticides leftovers and other waste related to pesticides are picked by competent organizations for safe disposal (Devi 2009; Jin et al. 2017). Further, and bizarrely to the environment, the respondents wash the sprayers after use in rivers, lakes or irrigation canals and throw empty or unused container on farms and in the nearby bushes. This appalling behavior and practices are the sources of pesticides contamination in the environment and strong regulatory practices and policies must be formulated and enacted to control the behavior. In most of the rural communities, rivers, lakes are the sources of drinking water and contamination by this approach must not be allowed. In addition, 
the ecological organisms would be affected if the intensity of these actions are not curtailed.

It is not surprising that the farmers reported health symptoms (headache, chest pain, weakness, etc.) during pesticide application. Burning sensation was first in ranking by the farmers followed by chest pain. A closer look at burning sensation revealed that it is the common symptom, but dependent on several explanatory variables. Logistic regression was used to model burning sensation and the associated explanatory variables to gain further insights regarding selected biosocial factors influencing burning sensation. The modeling (Table 9) revealed that factors likely to predispose burning sensation were knowledge to identify pests, knowledge to identify diseases, and wearing coverall. These variables were expected and shows clearly that farmers own intrinsic attributes such as ability to identify pest and diseases, and wearing coverall are within the reach of the farmers and can be managed effectively to minimize the burning sensation. In another study involving cocoa farmers, Okoffo et al. (2016) found educational level to be significant with respect to decision in wearing personal protective equipment. On the contrary in this study, low education was not significant. This might be due to strong social norms which was described by Feola and Binder (2010) and must be taken into account to have a behavioral change at collective and systematic level. Furthermore, educational training can help through policy intervention in addressing the health symptoms. In order to be sure of the modeling result of the sample size/distribution and estimation of the parameters, bootstrapping method was added as an internal mechanism to support the model. The result (Table 10) confirmed the strength and accuracy of the parameters estimated.

\section{Conclusions}

Watermelon production in Ghana is increasing due to export drive of the country. Similarly, the use of pesticide is growing to control pests and diseases by farmers in general. Understanding and documenting pesticide use is a prerequisite for any meaningful policy interventions. We investigated pesticides use by watermelon farmers in six communities in the Central region, Ghana. The result shows that farmers have knowledge and understanding of the hazardous nature of pesticides use. However, the knowledge about the environmental and health hazards of pesticide use is not translated into actual practice. Health hazards were reported and experienced by the farmers with various levels of symptoms. Burning sensation is the foremost symptom experienced by the farmers. Factors underlining and explanatory to the burning sensation were modeled. The most probable variables influencing burning sensation were knowledge to identify pests, knowledge to identify diseases, and wearing coverall. The implication is that educational training programs should be enhanced; extension services must be increased. The current farmer-extension officer ratio in Ghana is low and insufficient to cause any critical mass influence on farmers regarding the use of pesticides. The extension services and capacity should therefore be enhanced to increase the educational information flow. Pesticides retailers must be brought into the equation of pesticides education to augment the proper use of pesticides. The current approach of unregulated buying and usage without scientific base demands new policy interventions. With sound policy, heath risk impacts on the farmers and ecological implication and its' consequences would be minimized.

\section{Abbreviations}

MoFA: Ministry of Food and Agriculture; SPSS: Statistical Package for Social Sciences.

\section{Acknowledgements}

We thank Gabriel Addae, Extension Officer of the Ministry of Food and Agriculture (MoFA) for selfless service during data sampling.

\section{Authors' contributions}

MKM conceived and designed the work with APG, MK and DED validated the method section. All authors MKM; MK, APG, and DED participated in the analysis, validation and writing of the paper. All authors read and approved the final manuscript.

\section{Funding}

This study was not funded by any grant. We however, thank the Africa Centre of Excellence in Coastal Resilience (ACECoR)-Centre for Coastal Management, University of Cape Coast, Ghana for the payment of article publication charges.

\section{Availability of data and materials}

Part of the data that supports the findings are included in the manuscript. However, the raw data of the study are available from the corresponding author upon request.

\section{Ethics approval and consent to participate}

All participants agreed to participate in the research study, and they were free to participate with or without reservation.

\section{Consent for publication}

Consent to publish individual data in any form was obtained from the Watermelon farmers interviewed.

\section{Competing interests}

The authors declare that they have no competing interests.

\section{Author details}

${ }^{1}$ Department of Environmental Sciences, University of Cape Coast, North Campus, University Avenue, Science Building, Cape Coast, Ghana. ${ }^{2}$ ACECoRCentre for Coastal Management, University of Cape Coast, Cape Coast, Ghana.

${ }^{3}$ Department of Agricultural Economics and Extension, University of Cape Coast, Cape Coast, Ghana. ${ }^{4}$ Department of Soil Science, School of Agriculture, University of Ghana, Legon, Ghana.

Received: 23 January 2020 Accepted: 8 May 2020

Published online: 25 May 2020 


\section{References}

Afari-Sefa V, Asare-Bediako E, Kenyon L, Micah JA (2015) Pesticide use practices and perceptions of vegetable farmers in the Cocoa belts of the Ashnti and Western Regions of Ghana. Advan Crop Sci Technol 3:174. https://doi. org/10.4172/2329-883.1000174

Bewick V, Cheek L, Ball J (2005) Statistics review 14: logistic regression. Crit Care $9(1): 112-118$

Danso-Abbeam G, Ehiakpor DS, Aidoo R (2018) Agricultural extension and its effects on farm productivity and income: insight from Northern Ghana. Agric Food Secur 7:74. https://doi.org/10.1186/s40066-018-0225-x

Devi PI (2009) Healthrisk perceptions, awareness and handling behaviour of pesticides by farm workers. Agric Econ Res Rev 22:263-268

Mesele T, Dibaba K, Mendesil E (2019) Farmers' Perceptions of Mexican Bean Weevil, (Boheman), and Pest Management Practices in Southern Ethiopia. Adv Agric 2019:1-10

Donkor A, Osei-Fosu P, Dubey B, Kingsford-Adaboh R, Ziwu R, Asante I (2016) Pesticide residue in fruits and vegetables in Ghana: a review. Environ SciPoll Res 23:18966-18987

Efron B (1979) Bootstrap methods: another look at the jackknife. Ann Stat 7(1):26

Efron B (1985) Bootstrap confidence intervals for a class of parametric problems. Biometrika 72:45-48

Efron B, Tibshirani RJ (1993) An introduction to the bootstrap. Chapman and Hall, New York

Feola G, Binder CR (2010) Why don't pesticide applicators protect themselves? Exploring the use of personal protective equipment among Colombian smallholders. Int J Occup Environ Health 16:11-23

GSS (2014) Ghana Statistical Service: 2010 population and housing census. District analytical report. Komenda-Edina-Eguafo-Abrem Municipal. https ://www2.statsghana.gov.gh/docfiles/2010_District_Report/Central/KEEA. pdf./. Accessed 24 Apr 2020

Hosmer DW, Lemeshow S (2010) Applied logistic regression. Wiley, New York

Islam MM, Begum M (2018) Bootstrap confidence intervals for dissolution similarity factor $\mathrm{f}_{2}$. Biomet Biostat Int J 7:397-403

Jallow MF, Awadh DG, Albaho MS, Devi VY, Thomas BM (2017) Pesticide knowledge and safety practices among farm workers in Kuwait: results of a suvey. Int J Env Res Pub Health 14:340. https://doi.org/10.3390/ijerp h14040340

Jin J, Wang W, He R, Gong H (2017) Pesticide use and risk perceptions among small-scale farmers in Anqiu County, China. Int J Env Res Pub Health 14:29. https://doi.org/10.3390/ijerph14010029

Johnson RM, Ellis MD, Mullin CA, Frazier M (2010) Pesticides and honey bee toxicity-USA. Apidologie 41:312-331. https://doi.org/10.1051/apido /2010018

Kwadzo M, Annor-Frempong F, Lambon JB (2015) Pesticide use and health hazards among small-scale commercial vegetable growers in the
Nsawam Adoagyiri Municipality in the Eastern Region of Ghana. J Bio Agric Healthcare 5(18):156

Lorenz AN, Prapamontol T, Narksen W, Srinual N, Barr DB, Riederer AM (2012) Pilot study of pesticide knowledge, attitudes, and practices among pregnant women in Northern Thailand. Int J Env Res Pub Health 9:3365-3383. https://doi.org/10.3390/ijerph9093365

Machekano H, Masamba W, Mvumi BM, Nyamukondiwa C (2019) Cabbage or 'pesticide' on the platter? Chemical analysis reveals multiple and excessive residues in African vegetable markets. Int J Food Contam. https://doi org/10.1186/s40550-019-0072-y

Mattah MM, Mattah PA, Futagbi G (2015) Pesticide application among farmers in the catchment of Ashaiman irrigation scheme of Ghana: health implications. JEnv Pub Health. https://doi.org/10.1155/2015/547272

Ministry of Food and Agriculture (2015) Agriculture in Ghana: Facts and Figures 2015. Ghana. https://www.agrofood-westafrica.com/fileadmin/ user_upload/messen/agrofood-Westafrica/Brochure/AGRICULTURE-INGHANA-Facts-and-Figures-2015.pdf

Ngowi AV, Mbise TJ, ljani AS, London L, Ajayi OC (2007) Smallholder vegetable farmers in Northern Tanzania: pesticides use practices, perceptions, cost and health effects. Crop Protect. https://doi.org/10.1016/j.cropr 0.2007 .01 .008

Okoffo ED, Mensah M, Fosu-Mensah BY (2016) Pesticides exposure and the use of personal protective equipment by cocoa farmers in Ghana. Env Sys Res 5:17. https://doi.org/10.1186/s40068-016-0068-z

Osei-Fosu P, Donkor A, Ziwu C, Dubey B, Kingsford-Adaboh R, Asante I, Nyarko S, Tawiah R, Nazzah N (2017) Surveillance of pesticide residues in fruits and vegetables from Accra Metropolis markets, Ghana, 2010-2012: a case study in Sub-sahara Africa. Env Sci Poll Res 20:17187-17205

Strong LL, Thompson B, Koepsell TD, Meischke H (2008) Factors associated with pesticide safety practices in farmworkers. Am J Ind Med 51:69-81

Thompson B (1993) The use of statistical significance tests in research: bootstrap and other alternatives. JExp Edu 61:361-377

Thompson HM (2010) Risk assessment for honey bees and pesticides-recent development and 'new issues.' Pest Mang Sci 66:1157-1162. https://doi. org/10.1002/ps.1994

Wright DB, London K, Field AP (2011) Using bootstrap estimation and the plug-in principle for clinical psychology data. J Exp Psychopathol 2(2):252-270

Wumbei A, Houbraken M (2019) Pesticides use and exposure among yam farmers in the Nanumba traditional area of Ghana. Env Mon Assess. https ://doi.org/10.1007/s10661-019-7449-5

\section{Publisher's Note}

Springer Nature remains neutral with regard to jurisdictional claims in published maps and institutional affiliations.

\section{Submit your manuscript to a SpringerOpen ${ }^{\circ}$ journal and benefit from:}

- Convenient online submission

- Rigorous peer review

- Open access: articles freely available online

- High visibility within the field

- Retaining the copyright to your article

Submit your next manuscript at springeropen.com 